\title{
Teores de pigmentos fotossintéticos e estrutura de cloroplastos de Alfavaca-cravo cultivadas sob malhas coloridas
}

\author{
Pigments content and Alfavaca-cravo chloroplast structure cultivate under colored nets
}

\author{
Joeferson Reis Martins ${ }^{I}$ Amauri Alves de Alvarenga' ${ }^{I I}$ Evaristo Mauro de CastroII \\ Ana Paula Oliveira da Silva ${ }^{\mathrm{III}}$ Eduardo Alves $^{\mathrm{IV}}$
}

RESUMO

A Alfavaca-cravo é uma espécie medicinal produtora de óleo essencial de elevada eficácia no combate de diversos organismos patogênicos. Por isso, o entendimento do comportamento fisiológico dessa espécie e as respostas desse comportamento às condições do ambiente tornam-se necessários ao aperfeiçoamento dos métodos de cultivo. Nesse contexto, este estudo objetivou avaliar o efeito da intensidade e qualidade da luz nos teores de clorofila e carotenoides e na estrutura de cloroplastos de Alfavaca-cravo, Ocimum gratissimum L. As plantas com 5,0-6,0 cm foram submetidas aos seguintes tratamentos: pleno sol, sombreamento $50 \%$ sob malha azul, malha vermelha e malha preta durante 120 dias. As concentrações de clorofilas e carotenoides foram avaliadas por espectrofotometria, e as estruturas dos cloroplastos foram analisadas pela microscopia de transmissão. As plantas mantidas a pleno sol tiveram os menores teores de clorofila a e $b$ e o maior teor de carotenoides, enquanto aquelas cultivadas sob malha preta tiveram a maior concentração de clorofila a $e$ b. A menor densidade de cloroplastos foi encontrada nas plantas sob malha preta. Nos tratamentos com $50 \%$ de sombreamento, foram verificados cloroplastos mais alongados. As plantas de alfavaca-cravo crescidas a pleno sol e sob malha azul tiveram cloroplastos com maiores áreas e grãos de amido com maiores perímetros. As mudanças nas concentrações dos pigmentos e na estrutura dos cloroplastos evidenciaram uma adaptação da Alfavaca-cravo à variação de intensidade e qualidade da luz. Isso pode auxiliar no desempenho fotossintético sob diferentes condições luminosas.

Palavras-chave: Ocimum gratissimum, sombreamento, clorofila, carotenóides.

\begin{abstract}
The Alfavaca-cravo is a medicinal specie which produces an essential oil effective in the combat of several organisms. Therefore, the understanding of the physiologic behavior and physiological responses of this behavior to environmental conditions becomes necessary to improve methods of cultivation. In this context, the aim of this study was to evaluate the effect of the intensity and quality of the light on concentration of chlorophyll and carotenoids and on chloroplasts structure of Alfavaca-cravo (Ocimum gratissimum L.). The plants with $5.0-6.0 \mathrm{~cm}$ were submitted to the following treatments: full sunlight and $50 \%$ of shade under blue, red and black nets during 120 days. The chlorophyll and carotenoids concentration were analyzed through spectrophotometer and the structure of chloroplast was analyzed by transmission microscopy. Plants maintained under full sunlight had the lowest chlorophyll $a$ and $b$ concentration and the highest carotenoids concentration. However, plants cultivated under black net had the highest production of chlorophyll $a$ and $b$. The lowest chloroplasts density was found in plants under black net. In the treatments with $50 \%$ of shade was verified more elongated chloroplasts. Alfavaca-cravo plants grown under full sunlight and blue net had chloroplasts with larger areas and starch grains with larger perimeters. The changes on the pigments concentration and structure of chloroplasts showed a chromatic adaptation of Alfavaca-cravo to the variation of the intensity and quality of the light. This can improve photosynthetic performance under different luminosity conditions.
\end{abstract}

Key words: Ocimum gratissimum, shading, chlorophyll, carotenoids.

\footnotetext{
ISetor de Fisiologia Vegetal, Universidade Federal de Lavras (UFLA), 37200-000, Lavras, MG, Brasil. E-mail: joefersonreis@yahoo.com.br. Autor para correspondência.

IIDepartamento de Biologia, UFLA, Lavras, MG, Brasil.

IIIPró-reitoria de Planejamento e Gestão, UFLA, Lavras, MG, Brasil.

${ }^{\mathrm{IV}}$ Departamento de Fitopatologia, UFLA, Lavras, MG, Brasil.
} 


\section{INTRODUÇÃO}

Alfavaca-cravo, Ocimum gratissimum L., família Lamiaceae, é um subarbusto aromático originário da Ásia e África (LORENZI \& MATOS, 2002). Segundo PATON et al. (1999), o gênero Ocimum ocorre principalmente nas regiões quentes de ambos os hemisférios, ou seja, nos trópicos, onde há elevada radiação. No Brasil, a espécie é subespontânea em todo o território e é largamente utilizada na culinária e na medicina popular, no tratamento de diversos males, tais como: nervosismo, paralisia, tosse, vômitos e tuberculose(PIO CORRÊA, 1984; RODRIGUES, 1989).

Estudos recentes têm revelado o potencial bioativo do óleo essencial de $\boldsymbol{O}$. gratissimum L. sobre organismos de elevada patogenicidade, como Staphylococcus aureus, Bacillus spp, Pseudomonas aeruginosae, Klebisiella pneumoniae, Proteus mirabilis e Leishmania amazonensis (UEDANAKAMURA et al., 2006; MATASYOH et al., 2007). OGENDO et al. (2008) consideram o óleo essencial dessa espécie como alternativa natural aos inseticidas sintéticos no combate às pragas infestantes de grãos armazenados.

Tendo em vista sua importância medicinal, investigações a respeito do comportamento fisiológico dessa espécie e suas respostas às condições do ambiente tornam-se necessárias ao aperfeiçoamento dos métodos de cultivo. Dentre os fatores ambientais, a luz é um recurso fundamental para o desenvolvimento vegetal, pois muitas respostas morfofisiológicas não dependem apenas da presença, atenuação ou ausência da luz, mas também da variação de sua qualidade espectral (MORINI \& MULEO, 2003).

As alterações luminosas no ambiente de cultivo proporcionam ajustes do aparelho fotossintético das plantas, os quais resultam na maior eficiência na absorção e transferência de energia para os processos fotossintéticos. Nesse contexto, os teores dos pigmentos cloroplastídicos, clorofila e carotenoides podem ser utilizados como importantes marcadores de ambientação do vegetal.

De acordo com MARTINS et al. (2009), as alterações na intensidade e qualidade da luz também proporcionam profundas alterações na anatomia foliar da alfavaca-cravo, sobretudo na espessura foliar, na densidade de tricomas e nos estômatos. GONÇALVES (2001) observou variações ultraestruturais marcantes em resposta ao sombreamento de 50\% em Ocimum selloi, com diminuição da espessura dos parênquimas e aumento no número de estômatos e tricomas em relação a plantas cultivadas a pleno sol. No entanto, nas mesmas condições de sombreamento, COSTA et al. (2007) verificaram a diminuição da densidade de tricomas glandulares em plantas de $\boldsymbol{O}$. selloi. Esses estudos demonstram que o cultivo sob sombreamento de $50 \%$ pode proporcionar várias modificações relacionadas à produção de biomassa e formação de estruturas produtoras de metabólitos.

Em Arabidopsis, alterações na qualidade da luz promovem variações na quantidade de cloroplastos e em seu movimento nas células (LUESSE et al., 2006). SHAVER et al. (2008) verificaram que modulações na fluência de luz azul alteram a estrutura e as taxas de degradação de DNAs cloroplastídicos e a divisão plastídica em Medicago truncatula.

Segundo OREN-SHAMIR et al. (2001), as malhas coloridas diferem nos espectros de transmitância da radiação fotossinteticamente ativa. A malha azul apresenta um pico principal de transmitância na região do azul-verde (400-540nm), enquanto que a malha vermelha possui maior transmitância para comprimentos de ondas superiores a 590nm.

Tendo em vista a importância da radiação sob os diversos aspectos físiológicos e anatômicos nas espécies vegetais, o presente estudo teve por objetivo avaliar os efeitos do cultivo sob malhas de transmissão de luz diferenciada sobre os teores de clorofilas e carotenoides e sobre a anatomia dos cloroplastos em plantas de alfavaca-cravo. O trabalho busca caracterizar condições de cultivo que propiciem modificações em tais estruturas, uma vez que estas estão intimamente associadas à captação da energia luminosa e produção de metabólitos utilizados para o crescimento e desenvolvimento do vegetal.

\section{MATERIAL E MÉTODOS}

O experimento foi conduzido no Departamento de Biologia, da Universidade Federal de Lavras (UFLA), no período de janeiro a junho de 2006, sob condições de viveiro. As mudas de alfavaca-cravo foram produzidas a partir de sementes coletadas em plantas adultas, no Município de Lavras $\left(21^{\circ} 14^{\prime} \mathrm{S}\right.$, $45^{\circ} 00^{\prime}$ W GRW, altitude 918m), Minas Gerais (MG). Uma exsicata foi identificada pelo botânico Eduardo Van Den Berg e está depositada no Herbário ESAL sob o registro número 20.0037.

As sementes foram beneficiadas manualmente e semeadas em tubetes plásticos contendo substrato Plantmax ${ }^{\circledR}$ e mantidas em viveiro sob 50\% de sombreamento durante 60 dias. As mudas com 5,0-6,0cm de altura foram transplantadas para recipientes plásticos com capacidade para $6 \mathrm{~L}$ contendo substrato à base de terra de subsolo e areia, na proporção de 2:1, sem adubação adicional, e mantidas 
por 120 dias sob os tratamentos com malhas ChromatiNet de $50 \%$ de sombreamento, fornecidas pela empresa Polysac Plastic Industries ${ }^{\circledR}$, nas cores preta, vermelha e azul e a pleno sol. Em cada tratamento, foram empregadas 50 mudas, sendo uma planta por vaso, totalizando 200 plantas, com espaçamento de aproximadamente $40 \mathrm{~cm}$ entre os vasos.

No período do experimento, as plantas ficaram sujeitas às condições meteorológicas de Lavras-MG, cujo fotoperíodo médio foi de $7 \mathrm{~h} 30 \mathrm{~min}$, e a temperatura média foi de aproximadamente $20,5^{\circ} \mathrm{C}$. Segundo a classificação de Köppen, o clima de LavrasMG é do tipo Cwa, com duas estações bem definidas, uma fria e seca, de abril a setembro, e outra quente e úmida, de outubro a março. Os tratamentos foram irrigados diariamente, para manutenção do solo próximo da capacidade de campo.

A determinação dos teores de clorofila e carotenoides foi realizada ao final do experimento, a partir de sete folhas simples completamente expandidas do quarto nó abaixo do ápice das plantas, retiradas de sete plantas por tratamento, tomadas ao acaso. No momento da coleta, as folhas foram acondicionadas em papel alumínio e refrigeradas em gelo até serem transferidas ao laboratório. A extração e quantificação das clorofilas $a, b$ e total foram realizadas segundo a metodologia de ARNON (1949), a partir de 1g de matéria fresca homogeneizada em $50 \mathrm{~mL}$ de acetona $80 \%$, seguida de leitura em espectrofotômetro (Beckman, modelo 640 B) nos seguintes comprimentos de onda: 645 e $663 \mathrm{~nm}$. A concentração de carotenoides totais foi avaliada de acordo com metodologia descrita por DUKE \& KENYON (1986), utilizando os coeficientes de absortividade molar de SANDMANN \& BÖRGER (1983).

A avaliação da densidade e anatomia dos cloroplastos foi realizada por microscopia eletrônica de transmissão. Foram coletados fragmentos de aproximadamente $0,5 \mathrm{~cm}^{2}$, retirados da porção mediana de cinco folhas de cada tratamento, localizadas no $4^{\circ}$ nó abaixo do ápice, e fixados em solução de glutaraldeido $(2,5 \%)$ e paraformaldeido $(2,5 \%)$, em tampão cacodilato, $\mathrm{pH} 7,0,0,05 \mathrm{M}+\mathrm{CaCl}_{2} 0,001 \mathrm{M}$, por quatro horas, em temperatura ambiente. Os fragmentos foram lavados em tampão cacodilato $0,05 \mathrm{M}$ e pósfixados em tetróxido de ósmio $1 \%$ com o mesmo tampão, por quatro horas. Em seguida, o material foi desidratado em série cetônica e incluído em resina Spurr. Dos blocos obtidos foram feitas seções semifinas $(1 \mu \mathrm{m})$ e ultrafinas $(<100 \mathrm{~nm})$, por meio de ultramicrótomo Reichrt-Jung.

Os cortes semifinos foram corados com azul de toluidina e montados permanentemente em meio Permalt para a avaliação da densidade dos cloroplastos nas células do parênquima paliçádico em microscópio Olympus CBB. Os cortes ultrafinos foram coletados em grades de ouro e secos em raques de alumínio cobertos com formvar (ROWLEY \& MORAN, 1975). As seções foram pós-contrastadas em acetato de uranila, seguido por acetato de chumbo, e examinadas em microscópio eletrônico de transmissão Zeiss - EM 109. Nas análises ultraestruturais, foram avaliados a área, o perímetro e o comprimento dos cloroplastos e área e perímetro dos grãos de amido, em células do parênquima paliçádico. Nesse experimento, foram avaliados 10 cloroplastos em cada fragmento de folha, totalizando 50 avaliações para cada parâmetro analisado em cada tratamento. Os dados foram submetidos à análise de variância (ANAVA) e ao teste de Scott-knott $(\mathrm{P} \leq 0,05)$.

\section{RESULTADOS E DISCUSSÃO}

As concentrações de clorofilas e carotenoides apresentaram variação nos tratamentos usados (Tabela 1). Nos tratamentos sombreados, foram verificadas maiores concentrações de clorofilas e uma menor razão de clorofila $a$ e $b$ em relação às plantas cultivadas a pleno sol. As plantas que cresceram sob malha preta obtiveram maior produção de clorofilas $a$ e $b$, enquanto que nas plantas mantidas sob malhas azul e vermelha foram verificadas concentrações intermediárias. O aumento da proporção de clorofila $b$ nas plantas sombreadas pode ser considerado como característica importante de adaptabilidade vegetal em ambientes sombreados, uma vez que a clorofila $b$ absorve energia em comprimentos de onda diferentes da clorofila $a$ e a transfere para o centro de reação, maximizando, assim, a captura energética que efetivamente atua nas reações fotoquímicas (TAIZ \& ZEIGER, 2004).

Segundo LARCHER (2004), ecologicamente, as alterações na biossíntese de clorofilas pelas variações espectrais podem proporcionar vantagens quanto ao crescimento e sucesso reprodutivo das espécies vegetais. Assim, os resultados indicam a ocorrência de uma adaptação cromática da alfavaca-cravo que possivelmente auxilie no seu desempenho fotossintético.

As plantas cultivadas a pleno sol produziram maiores quantidades de carotenoides, os quais funcionam como moléculas fotoprotetoras por meio da rápida dissipação dos estados excitados da clorofila (GARCÍA-PLAZAOLA et al., 1999; TAIZ \& ZEIGER, 2004). Nos tratamentos com malhas vermelha e azul, foram observados teores intermediários de carotenoides. De acordo com OREN SHAMIR et al. 
Martins et al.

Tabela 1 - Teores de clorofilas $a, b$ e total ( $\mathrm{mg} \mathrm{g}^{-1}$ de matéria fresca), relação clorofila $a / b$ e teores de carotenoides totais em folhas de plantas de $\boldsymbol{O}$. gratissimum submetidas a diferentes condições de luminosidade. As malhas proporcionaram $50 \%$ de sombreamento.

\begin{tabular}{|c|c|c|c|c|c|}
\hline \multirow{2}{*}{ Tratamentos } & \multirow[b]{2}{*}{ Clorofila $a$} & \multirow[b]{2}{*}{ Clorofila $b$} & \multirow[b]{2}{*}{ Clorofila total } & \multirow[b]{2}{*}{ Clorofila $a / b$} & \multirow[b]{2}{*}{ Carotenoides } \\
\hline & & & & & \\
\hline Pleno sol & $0,194 \mathrm{c}^{*}$ & $0,060 \mathrm{~d}$ & $0,254 \mathrm{~d}$ & $3,230 \mathrm{a}$ & $1662,55 \mathrm{a}$ \\
\hline Malha preta & $0,413 \mathrm{a}$ & $0,141 \mathrm{a}$ & $0,554 \mathrm{a}$ & $2,929 \mathrm{~b}$ & $951,05 \mathrm{~d}$ \\
\hline Malha vermelha & $0,249 \mathrm{c}$ & $0,092 \mathrm{c}$ & $0,341 \mathrm{c}$ & $2,706 \mathrm{c}$ & $1285,17 \mathrm{~b}$ \\
\hline Malha azul & $0,308 \mathrm{~b}$ & $0,111 b$ & $0,419 \mathrm{~b}$ & $2,774 \mathrm{c}$ & $1136,92 \mathrm{c}$ \\
\hline
\end{tabular}

*Médias seguidas por letras distintas na coluna diferem estatisticamente entre si pelo teste de Scott-knott $(\mathrm{P}=0,05)$.

(2001), o ambiente sombreado com malha azul apresenta maior transmitância da luz na faixa do azul (400-500nm), indicando que o balanço energético possa favorecer a absorção energética pelos carotenoides e, uma vez que estes estão associados às moléculas de clorofilas dos sistemas antenas e aos centros de reação, têm a capacidade auxiliar o desempenho fotossintético por meio da transferência de energia absorvida para as clorofilas.

O número de cloroplasto por célula não variou entre as plantas a pleno sol, sob malha azul e malha vermelha (Tabela 2). O cultivo sob malha preta proporcionou uma redução de aproximadamente $60 \%$ do número de cloroplastos por célula em relação aos demais tratamentos sombreados. COSTA et al. (2007) verificaram em Ocimum selloi um acréscimo na densidade de cloroplastos em plantas crescidas sob malha azul e malha vermelha. Em Mikania laevigata, o cultivo sob malha azul proporcionou a maior densidade de cloroplastos no parênquima paliçádico (SOUZA et al., 2007). Esses resultados expressam que a biogênese dos cloroplastos em alfavaca-cravo pode ser controlada por alterações na intensidade e na qualidade espectral da radiação no ambiente de cultivo. JIAO et al. (2007) e RUCKLE et al. (2007) demonstraram que a rota de transdução de sinal para a biossíntese de cloroplasto envolve criptocromos sensíveis às variações no conteúdo de luz azul da radiação total.
Os cloroplastos das plantas crescidas a pleno sol e sob malha azul apresentaram maiores área e perímetro. No entanto, em todos os tratamentos sombreados foram verificados cloroplastos mais alongados, com disposição periclinal e aderidos à parede celular. Comportamento semelhante foi descrito em $\boldsymbol{O}$. selloi, que também apresentou cloroplastos mais alongados sob sombreamento de $50 \%$, tanto sob malha vermelha, como sob malha azul, em relação às plantas a pleno sol (COSTA et al., 2007). De acordo com LUESSE et al. (2006), o alongamento e a disposição periclinal dos cloroplastos aumentam a absorção da luz e consequentemente a eficiência fotossintética em ambientes sombreados.

Em todos os tratamentos foi observado que os cloroplastos continham um único grão de amido (Figura 1). As plantas a pleno sol e sob malha azul apresentaram grãos de amido com os maiores perímetros (Tabela 2). Isso indica que essas condições de cultivo podem proporcionar maiores acúmulos de reserva energética nas células do mesofilo, sendo uma característica vantajosa para o crescimento e a produtividade da alfavaca-cravo. MARTINS et al. (2008) verificaram que plantas de alfavaca-cravo crescidas sob malha azul apresentaram maior alocação de matéria seca para o caule, maior crescimento em altura e maior teor de óleo essencial nas folhas.

Tabela 2 - Valores médios das características cloroplastídicas do tecido paliçádico de plantas jovens de $\boldsymbol{O}$. gratissimum L. submetidas a diferentes condições de luminosidades, com $50 \%$ de sombreamento sob malhas. Legenda: Dens=densidade; Perim=perímetro; Comp=comprimento.

\begin{tabular}{|c|c|c|c|c|c|c|}
\hline \multirow{2}{*}{ Tratamentos } & \multicolumn{4}{|c|}{-----------------------Características cloroplastídicas----------------------- } & \multicolumn{2}{|c|}{----------Grão de amido---------- } \\
\hline & Dens $\left(\mathrm{n}^{\mathrm{o}}\right.$ célula $\left.^{-1}\right)$ & Área $\left(\mu \mathrm{m}^{2}\right)$ & Perim $(\mu \mathrm{m})$ & Comp $(\mu \mathrm{m})$ & Largura $(\mu \mathrm{m})$ & Perim $(\mu \mathrm{m})$ \\
\hline Pleno sol & $11,4 \mathrm{a}^{*}$ & $15,63 \mathrm{a}$ & $17,55 \mathrm{a}$ & $5,34 \mathrm{~b}$ & $3,70 \mathrm{a}$ & $14,04 \mathrm{a}$ \\
\hline Malha preta & $7,50 \mathrm{~b}$ & $10,23 \mathrm{~b}$ & $16,66 \mathrm{~b}$ & $6,36 \mathrm{a}$ & $2,30 \mathrm{c}$ & $10,65 \mathrm{c}$ \\
\hline Malha vermelha & $12,10 \mathrm{a}$ & $12,75 \mathrm{~b}$ & $17,29 \mathrm{~b}$ & $6,21 \mathrm{a}$ & $2,83 \mathrm{~b}$ & $12,51 \mathrm{~b}$ \\
\hline Malha azul & $12,60 \mathrm{a}$ & $15,45 \mathrm{a}$ & $18,66 \mathrm{a}$ & $5,94 \mathrm{a}$ & $3,15 \mathrm{~b}$ & $13,68 \mathrm{a}$ \\
\hline
\end{tabular}

* Médias seguidas por letras distintas na coluna diferem estatisticamente entre si pelo teste de Scott-knott $(\mathrm{P}=0,05)$. 


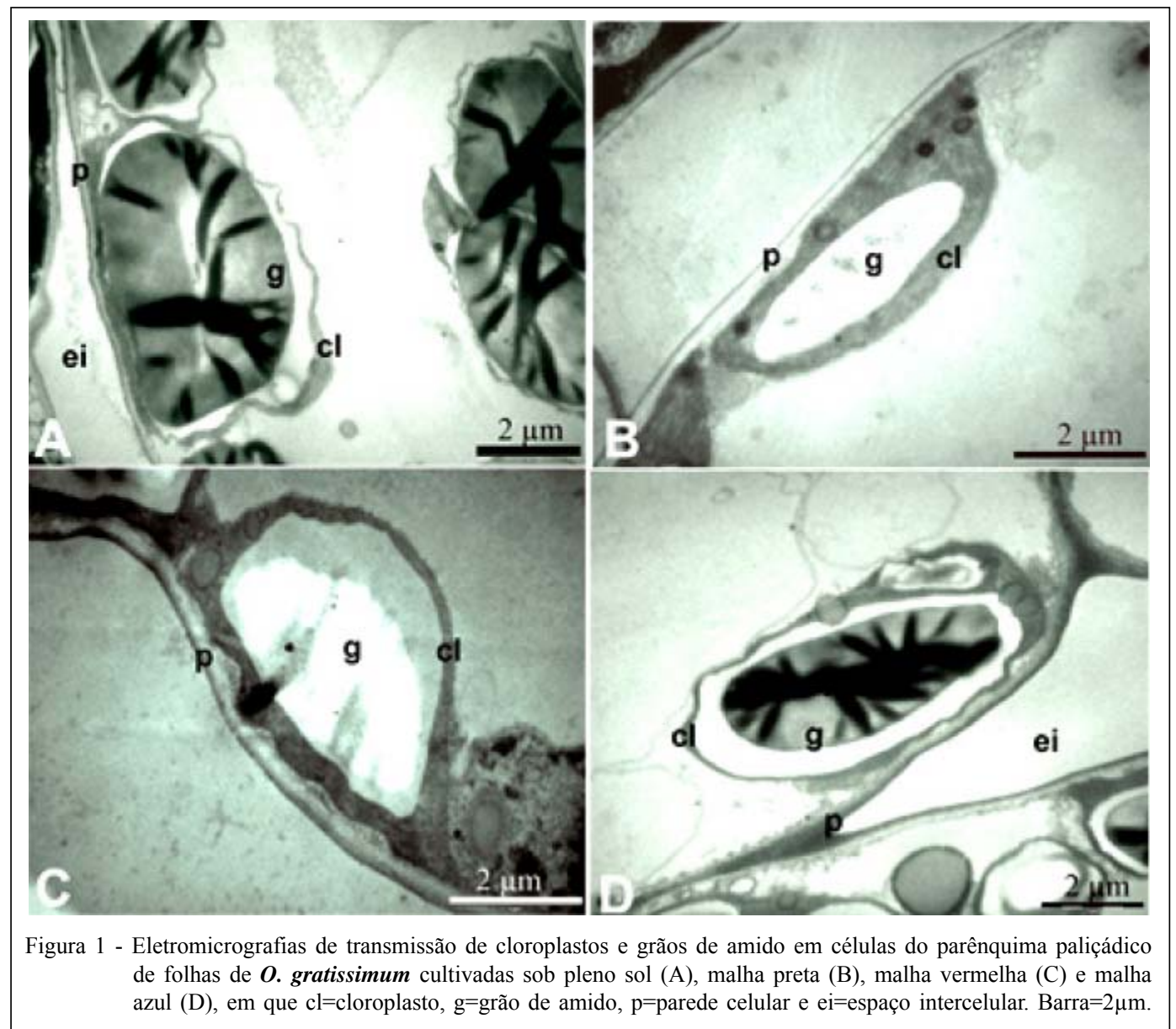

\section{CONCLUSÃO}

O cultivo sob malha azul proporciona a produção de cloroplastos com maior reserva energética e evita a alta produção de carotenoides. Essas mudanças verificadas nas concentrações dos pigmentos e na estrutura dos cloroplastos evidenciam uma adaptação de alfavaca-cravo à variação cromática que objetiva melhorar o desempenho fotossintético e permite inferir que o controle na radiação luminosa pode ser usado no cultivo dessa espécie para otimizar seu crescimento e sua produtividade.

\section{REFERÊNCIAS}

ARNON, D.I. Copper enzymes in isolates choroplasts. Polyphenoloxidade in Beta vulgaris. Plant Physiology, v.24, n.1, p.1-15, 1949.

COSTA, L.C.B. et al. Aspectos da anatomia foliar de Ocimum selloi Benth. (Lamiaceae) em diferentes condições de qualidade de luz. Revista Brasileira de Biociências, v.5, supl.1, p.68, 2007.
DUKE, S.O.; KENYON, W.H. Effects of dimethazone (FMC 57020 ) on chloroplast development II. Pigment synthesis and photosynthetic function in cowpea (Vigna unguiculata L.) primary leaves. Pesticide Biochemistry and Physiology, v.25, n.1, p.11-18, 1986.

GARCÍA-PLAZAOLA, J.I. et al. Diurnal changes in antioxidant and carotenoid composition in the Mediterranean schlerophyll tree Quercus ilex (L.) during winter. Plant Science, v.143, n.2, p.125-133, 1999. Disponível em: <http://www.sciencedirect.com/ science?_ob=ArticleURL\&_udi=B6TBH-3WNMGG3$1 \&$ user $=686380 \&$ rdoc $=1 \&$ fmt $=\&$ orig $=$ search \& sort $=\mathrm{d} \&$ docanchor $=\&$ view $=$ c\&_acct $=\bar{C} 000037521 \&$ _version $=1 \&$ \&urlV

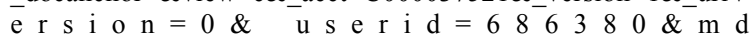
$5=97 \mathrm{~b} 417 \mathrm{e} 21 \mathrm{db} 56 \mathrm{cb} 8 \mathrm{c} 171 \mathrm{c} 047 \mathrm{cc} 20 \mathrm{~b} 885>$. Acesso em: 2 set. 2009. doi:10.1016/S0168-9452(99)00034-5.

GONÇALVES, L.A. Ontogenia dos tricomas glandulares e influência da radiação solar no desenvolvimento e no teor de óleo essencial de Ocimum selloi Benth (Lamiaceae). 2001. 95f. Dissertação (Mestrado em Botânica) - Universidade Federal de Viçosa, Viçosa, MG.

JIAO, Y. et al. Light-regulated transcriptional networks in higher plants. Nature Reviews Genetics, v.8, p.217-230, 2007. Disponível em: http://www.nature.com/nrg/journal/v8/ n3/pdf/nrg2049.pdf>. Acesso em: 2 set. 2009. doi: 10.1038/ nrg2049. 
LARCHER, W. Ecofisiologia vegetal. São Carlos: RiMA Artes e Textos, 2004. 531p.

LORENZI, H.; MATOS, F.J.A. Plantas medicinais do Brasil: nativas e exóticas. Nova Odessa: Instituto Plantarum de Estudos da Flora, 2002. 512p.

LUESSE, S.L. et al. Plastid movement impaired 2, a new gene involved in normal blue-light-induced chloroplast movements in Arabidopsis. Plant Physiology, v.141, p.1328-1337, 2006. Disponível em: < http://www.plantphysiol.org/cgi/reprint/141/ 4/1328.pdf>. Acesso em: 2 set. 2009. doi: 10.1104/ pp. 106.080333

MARTINS, J.R. et al. Anatomia foliar de plantas de alfavacacravo cultivadas sob malhas coloridas. Ciência Rural. v.39, n.1, p.82-87, 2009. Disponível em: <http://www.scielo.br/pdf/ cr/v39n1/a40cr193.pdf>. Acesso em: 2 set. 2009. doi: 10.1590/ S0103-84782008005000040.

MARTINS, J.R. et al. Avaliação do crescimento e do teor de óleo essencial em plantas de Ocimum gratissimum L. cultivadas sob malhas coloridas. Revista Brasileira de Plantas Medicinais, v.10, n.4, p.102-107, 2008. Disponível em: $<$ http://www.ibb.unesp.br/servicos/publicacoes/rbpm/ pdf v10 n4 2008/artigo15 p102-106.pdf >. Acesso em: 2 set 2009 .

MATASYOH, L.G. et al. Chemical composition and antimicrobial activity of the essential oil of Ocimum gratissimum L. growing in Eastern Kenya. African Journal of Biotechnology, v.6, n.6, p.760-765, 2007. Disponível em: < http://www.academicjournals.org/AJB/PDF/pdf2007/ 19Mar/Matasyoh\%20et\%20al.pdf>. Acesso em: 2 set. 2009.

MORINI, S.; MULEO, R. Effects of light quality on micropropagation of woody species. In: JAIN, S.M.; ISHII, K. Micropropagation of woody trees and fruits. Dordrecht: Kluwer Academic, 2003. p.3-35.

OGENDO, J.O. et al. Bioactivity of Ocimum gratissimum L. oil and two of its constituents against five insect pests attacking stored food products. Journal of Stored Products Research, v.44, p.328-334, 2008. Disponível em: <http://www.sciencedirect.com/ science?_ob=MImg\&_imagekey=B6T8Y-4S SP76B-1$7 \&$ \& di $=5099 \&$ \& user $=686380 \&$ \&_orig=browse $\&$ _c o verDat e $=12 \% 2$ F $31 \% 2$ F $2008 \&$ \& k $=$ 999559995 \& vi e w $=\mathrm{c} \& \mathrm{w} \mathrm{c}$ h p $=\mathrm{d}$ G L z V z z zSkWA\&md5=48456124598e 74df28bcd0bdb7fd28c8\&ie=/ sdarticle.pdf>. Acesso em: 2 set. 2009. doi: 10.1016/ j.jspr.2008.02.009.

OREN-SHAMIR, M. et al. Colored shade nets can improve the yield and quality of green decorative branches of Pittosphorum variegatum. Journal of Horticultural Science and Biotechnology, v.76, n.3, p.353-361, 2001.

PATON, A. et al. Ocimum: an overview of classification and relationships. In: HOLM, Y.; HILTUNEN, R. (Ed.). Ocimum: medicinal and aromatics plants industrial profiles. Series. Amsterdan: Hardman, 1999. p.1-38.

PIO-CORRÊA, M. Dicionário das plantas úteis do Brasil e das exóticas cultivadas. 2.ed. Rio de Janeiro: Imprensa Nacional, 1984. V.6.

RODRIGUES, R.M. A flora da Amazônia. Belém: CEJUP, 1989. 462p.

ROWLEY, C.R.; MORAN, D.T. A simple procedure for mounting wrinkle free section on formvar-coated slot grids. Ultramicrotomy, Amsterdam, v.1, n.2, p.151-155, 1975.

RUCKLE, M.E. et al. Plastid signals remodel light signaling networks and are essential for efficient chloroplast biogenesis in Arabidopsis. Plant Cell, v.19, p.3944-3960, 2007. Disponível em: <http://www.plantcell.org/cgi/content/full/19/ $12 / 3944$ ? $\mathrm{maxtoshow}=\&$ H I S $=10 \& \mathrm{hits}=10 \& \mathrm{R}$ ESULTFORMAT $=\&$ andorexactitle $=$ and $\&$ and orexacttitleabs $=$ and $\&$ andorexactfulltext $=$ and $\&$ searchid $=1 \&$ F I R S T I N D E X $=0 \& \mathrm{~s}$ o r t s p e c $=\mathrm{re} 1 \mathrm{e} \mathrm{v}$ ance $\&$ volume $=19 \&$ resourcetype $=$ HWCIT $>$. Acesso em: 2 set. 2009. doi: 10.1105/tpc.107.054312.

SANDMANN, G; BÖGER, P. Comporison of the bleaching activity of Norflurazon and Oxyfluorfen. Weed Science, v.31, n.3, p.338-341, 1983.

SHAVER, D.J. et al. The structure of chloroplast DNA molecules and the effects of light on the amount of chloroplast DNA during development in Medicago truncatula. Plant Physiology, v.146, p.1064-1074, 2008. Disponível em: <http:/ /www.plantphysiol.org/cgi/content/full/146/3/ 1064 ? $\mathrm{maxt}$ o s how $=\&$ H I T S $=10 \& \mathrm{hits}=10 \&$ RESULTFORMAT $=\&$ author $1=$ shaver $\&$ andorexactitle $=\mathrm{a}$ nd\&andorexacttitleabs $=$ and $\&$ andorexactfulltex $\mathrm{t}=$ and $\&$ sear $\mathrm{c} \mathrm{h} \mathrm{i} \mathrm{d}=1 \&$ F I R S T I N D E X $=0$ \& s or t s p e c $=$ re 1 evance $\&$ volume $=146 \&$ resourcetype $=$ HWCIT $>$. Acesso em: 2 set. 2009. doi: 10.1104/pp.107.112946.

SOUZA, G.S. et al. Estrutura foliar e de cloroplastídeos de Mikania laevigata Shultz Bip. Ex Baker em diferentes condições de qualidade de luz. Revista Brasileira de Biociências, v.5, supl.1, p. 8-80, 2007.

TAIZ, L.; ZEIGER, E. Fisiologia vegetal. 3.ed. Porto Alegre: Artmed, 2004. 719p.

UEDA-NAKAMURA, T. et al. Antileishmanial activity of Eugenolrich essential oil from Ocimum gratissimum. Parasitology International, v.55, n.2, p.99-105, 2006. Disponível em: $<\mathrm{http} /$ /www.sciencedirect.com/science?_ob=MImg\&_imagekey=B6TB74 H T CW 8 N-2-9\& cdi=5 135 \& user $=686380 \&$ o rig $=$ browse \&_coverDate $=06 \% 2$ F $30 \% 2$ F 200 $6 \&$ \& s $=999449997 \&$ view $=\mathrm{c} \& \mathrm{wchp}=\mathrm{d} \mathrm{G} \mathrm{LbVzz}-$ zSkWz\&md5=fce0bbafe9d50e1918e849fc0e3b8727\&ie=/ sdarticle.pdf $>$. Acesso em: 2 set. 2009. doi: 10.1016/ j.parint.2005.10.006. 